\title{
INOVAÇÃO E CIÊNCIAS SOCIAIS: em busca de novos referenciais
}

\section{Thales de Andrade}

\section{Introdução}

Inovação é uma daquelas palavras carentes de definição precisa e que são defendidas por grupos sociais os mais diversos. De forma semelhante a outros conceitos como globalização e desenvolvimento sustentável, é um termo extremamente polissêmico e consensual, tido por muitos como a tábua de salvação para todos os problemas que envolvem tecnologia e crescimento econômico.

Nos países avançados, a temática da inovação adentrou na agenda de diferentes setores, e desde os anos de 1980 os países da Organização para Cooperação e Desenvolvimento Econômico (OCDE) vêm alterando o padrão de apoio à indústria, incorporando medidas de inovação que

Artigo recebido em dezembro/2003

Aprovado em abril/2005 integram a política de comércio internacional com a industrial e tecnológica. Em vez de subvencionarem empresas por meio de contratos de Pesquisa e Desenvolvimento (P\&D) específicos e pontuais, os governos desses países passaram a criar condições para que a atividade produtiva se organizasse de forma sistêmica e integrativa (Cassiolato e Lastres, 2000).

No Brasil assistiu-se a partir de meados dos anos de 1990 a um investimento crescente em políticas de inovação. A criação dos fundos setoriais para financiamento de pesquisas, a formulação da Lei de Inovação e o crescimento na importância das Incubadoras de Empresas apontam para a tendência de se integrar experiências e práticas de inovação tecnológica (Lemos, 2000).

Regras de propriedade intelectual, formação de redes de pesquisa e sinergias entre setores público e privado na área tecnológica são questões 
que têm ocupado a atenção dos formuladores de políticas. Apesar de ainda ser prematuro avaliar os impactos dessas políticas na sociedade brasileira, elas demonstram que a temática da inovação penetrou na agenda pública do país (Trigueiro, 2002).

A trajetória dessa discussão é extremamente fecunda sob diversos aspectos. Tem possibilitado uma reflexão sobre mudanças nos comportamentos corporativos; a articulação de setores públicos de pesquisa com a iniciativa privada; a formulação de redes de pesquisa e desenvolvimento; e outras contribuições nas áreas de contato entre empresas, centros de pesquisa, universidades e setor público (Lemos, 2000).

Mas se observa que a área de ciências sociais não está inserida tão fortemente nessa agenda de pesquisa, em comparação com a economia e as ciências organizacionais. Desde seus fundadores, os cientistas sociais muitas vezes se ocuparam da problemática tecnológica, discutindo seus impactos nas relações sociais e nas formas de exploração do trabalho, mas freqüentemente se esquivando de debater o fenômeno técnico em si mesmo e a questão da inovação (Feenberg, 1991).

Mais recentemente, os teóricos do risco social apontaram a crise das certezas do mundo contemporâneo, em que a contingência e a instabilidade das práticas tecnológicas repercutem diretamente na sociabilidade. O princípio de precaução e a desconfiança no desenvolvimento tecnológico passaram a ter grande presença no pensamento social contemporâneo (Brueseke, 2002).

O tema da inovação tem se mantido estreitamente ligado a preocupações de ordem econômica, como competitividade e pressões da demanda e investimento. Alguns autores chamam a atenção para o desafio premente de incluir variáveis socioculturais nas avaliações e nos estudos sobre a implementação da inovação em contextos locais e nacionais. Os conceitos de contexto tecnológico e de ambientes de inovação representam novas possibilidades de incorporar teórica e empiricamente práticas de inovação em uma dimensão sociológica (Flichy, 1995; Maciel, 1997).

O propósito deste artigo consiste em realizar uma discussão exploratória acerca das articula- ções possíveis entre as ciências sociais e a problemática da inovação, de maneira a apontar o potencial dessa área do conhecimento para tratar esse tema. Em um primeiro momento, será feito um breve balanço das tendências preponderantes da análise sobre inovação.

Posteriormente serão discutidas as contribuições de sociólogos como Bruno Latour, Maria Lúcia Maciel e Manuel Castells, que trabalham com conceitos que permitem adicionar questões à agenda schumpeteriana sobre o tema da inovação. As noções de ambientes de inovação, contextos e tradução têm o potencial de inserir novas variáveis nesse debate.

Em seguida, será discutida a problemática da indeterminação do processo inovativo, tema que mobiliza diversos autores na área de ciências sociais e reforça os principais argumentos deste artigo.

\section{O conceito de inovação tecnológica}

Sem pretender esgotar o tema, já tratado por diversos autores, o intuito desta seção consiste em contextualizar a emergência e a consolidação do conceito de inovação no quadro teórico mais recente.

A disciplina econômica foi a que sem dúvida deu o maior impulso à construção da agenda da inovação. As elaborações de Joseph Schumpeter no início do século XX tiveram um impacto considerável no debate sobre transformações tecnológicas e desenvolvimento econômico.

Segundo ele, os investimentos nas novas combinações de produtos e processos produtivos de uma empresa repercutem diretamente em seu desempenho financeiro, de modo que o moderno empresário capitalista deve ocupar ao mesmo tempo um papel de liderança econômica e tecnológica. O comportamento empreendedor, com a introdução e a ampliação de inovações tecnológicas e organizacionais nas empresas, constitui um fator essencial para as transformações na esfera econômica e seu desenvolvimento no longo prazo (Schumpeter, 1982). 
$\mathrm{Na}$ esteira das elaborações de Schumpeter, há algumas décadas o termo inovação foi cunhado no âmbito da OCDE com vistas a promover uma interação mais efetiva entre o setor produtivo e as áreas de pesquisa e conhecimento. Isso ocorreu no momento em que a abertura de mercados e o aumento da competitividade internacional incitaram empresas e governos a estabelecerem sinergias envolvendo pesquisa tecnológica e política industrial, para a manutenção das taxas de crescimento econômico.

O economista Christopher Freeman, considerado um autor neo-schumpeteriano, foi o responsável pelo estabelecimento do conceito em sua versão atual. Desde os anos de 1960, essa discussão surge e se desenvolve com um claro perfil corporativo, sendo vista como condição para que empresas e governos tenham um bom desempenho na economia internacional em face das oscilações de mercado e de ameaças da concorrência (ver Freeman, 1982; 1992).

Diferentes perspectivas de análise foram construídas para lidar com a questão da inovação. Uma das primeiras vertentes da pesquisa sobre inovação foi a teoria da "hélice tripla", que se propunha a entender os processos inovadores a partir da conjugação de três segmentos: empresas, universidades e o Estado. O encontro entre pesquisadores, formuladores de políticas e empresários garantiria o desenvolvimento de empreendimentos cruzados de atividade científica e tecnológica.

O grande problema enfrentado pelas análises baseadas na perspectiva tradicional da hélice tripla é que elas atendiam geralmente em inovações pontuais e específicas. Dava-se, dessa forma, uma grande ênfase aos produtos gerados pela atividade tecnológica, pelos setores produtivos (clusters), e sua capacidade de entrada no mercado, independentemente dos formatos institucionais subjacentes a cada processo de inovação e dos impactos sociais decorrentes.

De grande destaque nas últimas décadas, essa perspectiva de análise levou à formulação de diversos modelos de inovação e projeções macroeconômicas. O cruzamento de informações so- bre patenteamento de produtos e investimentos públicos e privados na área tecnológica, por exemplo, permitiu a elaboração de fórmulas e modelos para se avaliar os efeitos do mercado sobre as práticas de inovação, a célebre problemática da indução pela demanda (Flichy, 1995).

Um recorte essencialmente quantitativo e linear, assentado no cruzamento de dados sobre aquisição de patentes e investimentos em pesquisa básica e avançada, deu o tom das investigações sobre o processo de inovação na atividade industrial. A ligação estreita e mecânica entre avanço tecnológico e comportamento econômico dominou os estudos sobre inovação durante décadas, conforme observado por diversos autores (Maciel, 2001).

Segundo Flichy (1995), um sério problema metodológico persegue essas teorias que procuraram estabelecer as relações entre pressão da demanda, oferta tecnológica e inovação. Elas propiciaram modelos e cruzaram determinadas variáveis, mas não lograram explicar como os processos inovativos aparecem e se desenvolvem.

Por um lado, essas análises estabeleceram categorias importantes para se entender o fenômeno da inovação, mas, por outro, mantiveram esquemas lineares e deterministas de explicação. As relações exógenas entre ciência e tecnologia e os modelos mecânicos de interferência da demanda sobre a atividade tecnológica mostraram-se insuficientes para esclarecer por que determinadas inovações tiveram êxito e outras não. Além disso, tais análises não permitem perceber que a inovação possui um ritmo técnico próprio que não se submete totalmente às modificações do mercado e que esse último também é condicionado por mudanças nas práticas tecnológicas (Nicolas e Mytelka, 1994; Maciel, 2001).

A partir dos anos de 1980, os economistas passaram a mudar o enfoque de análise. Os produtos específicos a serem desenvolvidos e os efeitos da oferta de recursos e da demanda de trabalho na indução à inovação deixaram de representar o centro das atenções da prática inovativa. Com a globalização da economia e a flexibilização dos formatos organizacionais envolvendo empresas, agências es- 
tatais e centros de pesquisa, a formação e o desenvolvimento de redes passaram a ser um tema central das pesquisas sobre inovação (Freeman, 1992).

Nesse contexto, em que a estrutura organizacional assentada nos fluxos de informação passa a ser mais essencial que os próprios produtos desenvolvidos a partir das atividades tecnológicas, estabelece-se um novo conceito, o de sistemas nacionais de inovação (Cassiolato e Lastres, 2000).

Esse conceito, que adquiriu grande primazia durante os anos de 1990, advoga que as interações entre os agentes econômicos, as instituições de pesquisa e os organismos governamentais estipulam ações recíprocas que geram a capacidade de desenvolvimento de condições de inovação. Nesse sentido, políticas locais e setorizadas passaram a ser imprescindíveis para a compreensão do potencial inovativo de uma nação e região, independentemente da atividade específica de cada setor e das oscilações da demanda.

A construção de novos formatos organizacionais e a ênfase em atividades de parceria, prestação de serviços, intercâmbios e convênios envolvendo empresas, governos, universidades, incubadoras e centros de pesquisa em regras múltiplas e variáveis passaram a constituir a precondição para qualquer inovação.

A crítica aos padrões lineares e simplistas de inovação, que enfocavam as relações estritas entre mercado e indústria, permitiu a construção não só de um programa de pesquisa centrado na difusão de informações e conhecimento, mas também de novas variáveis de análise. A partir desse momento, algumas análises econômicas começaram a manifestar a necessidade de ampliação da agenda de pesquisa centrada em inovação tecnológica.

O trabalho de Nicolas e Mytelka (1994) é um exemplo de análise econômica que discute essas abordagens convencionais, procurando inserir outras variáveis na pesquisa sobre inovação. Segundo os autores, os economistas neo-schumpeterianos

[...] abstraem o fato de que a tecnologia seja uma construção social, determinada não somente pela acumulação de conhecimentos, mas também pelas forças sociais, necessidades econômicas, decisões políticas e pelas pressões públicas que influenciam a direção da mudança tecnológica [...]. Adotar uma definição estreita da noção de progresso tecnológico e torná-lo o motor de toda uma cadeia de acontecimentos faz com que um processo dinâmico pareça estático e linear [...] (1994, p. 7).

Se a princípio essa problemática tinha um foco estritamente econômico, produtivo, atualmente ela precisa incorporar variáveis culturais, sociais e políticas. Faz-se necessário, pois, expandir o conceito de inovação de forma a incluir as condições coletivas para a qualificação de profissionais, a inclusão de setores marginalizados, a revitalização do espaço urbano, entre outras.

Ainda segundo esses autores, o conceito de sistemas nacionais de inovação, formulado por economistas e administradores ao longo dos anos de 1970 e 1980, foi importante uma vez que ampliou a organização, os formatos institucionais e o financiamento da atividade inovadora. Mas ele não conseguiu alterar significativamente o elenco de agentes envolvidos nas práticas da inovação sobretudo universidades, empresas e órgãos governamentais.

\section{Contextos e ambientes}

A partir dos anos de 1970, o pensamento sociológico começou a adentrar no debate sobre inovação trazendo novas perspectivas de análise. Uma das grandes críticas dos cientistas sociais à tradição schumpeteriana reside no determinismo e na abstração dos modelos de inovação, que precisam dar lugar a uma abordagem circunstancial e multilinear, que não aceitam como auto-suficientes os parâmetros das escolhas racionais.

Entre os vários autores que tratam desse tema, foram escolhidos três sociólogos para embasar a presente análise: Bruno Latour, Maria Lúcia Maciel e Manuel Castells. Apesar das especificidades de cada um, suas contribuições são relevantes para se estabelecer uma agenda sociológica para a tema da inovação. 
A obra de Bruno Latour sem dúvida tem apresentado novos parâmetros para a perspectiva da inovação em confronto à tradição estabelecida a partir de Schumpeter. Fatores importantes da análise econômica, como mecanismos de mercado e progresso técnico, passam a ter sua capacidade explicativa questionada por abordagens que privilegiam as relações circunstanciais da prática inovativa.

Segundo Latour, que dirige o Centro de Sociologia da Inovação na Escola de Minas em Paris, toda inovação deve se construir a partir daquilo que ele denomina ação estratégica dos inovadores. Nessa ação estratégica, o inovador precisa ao mesmo tempo controlar o contexto social em que se desenrola a prática inovadora e se adaptar a ele (Latour, 2000).

O conceito de contexto adquire importância capital em sua sociologia da inovação. Em suas práticas, os agentes inovadores ao mesmo tempo constroem e se submetem aos seus respectivos contextos de inovação. Toda inovação solicita um contexto que lhe seja favorável e, caso seja impedido de manipular tal ambiente, o agente inovador se verá incapacitado para impor novas regras de articulação entre as tecnologias e o comportamento social. O social e o técnico possuem uma recorrência mútua que o pensamento técnico tradicional não foi capaz de identificar (Latour, 1992).

A externalidade entre o técnico e o social se desfaz à medida que os sistemas ampliam sua abrangência e constroem para si mesmos seu próprios ambientes. A implementação de dispositivos multifuncionais e de alta compatibilidade externa e interna é uma necessidade fundamental para atender demandas complexas, e o caminho para esse encadeamento se faz mediante a tradução de propriedades técnicas e sociais anteriormente dispersas, como no caso do projeto do metrô Aramis em Paris (Idem).

Em sua análise sobre a construção de Aramis e sua crise ao longo dos anos de 1980, Latour aponta que se conforma em torno dele uma troca incessante de informações e conhecimento, que só se pode constituir a contento mediante uma conjugação complexa de fatores diversificados. Este é um exemplo de projeto de inovação que se propunha a promover impactos profundos sobre setores técnicos e leigos de forma imprevisível e cambiante, representando a constituição de um novo contexto técnico e social na confluência entre o espaço urbano, os recursos tecnológicos, os posicionamentos jurídicos e o imaginário dos consumidores.

Policy makers, técnicos em engenharia, urbanistas e consumidores passaram a configurar um contexto social de argumentações em torno dessa inovação. Nesse contexto, os setores tradicionais do paradigma schumpeteriano, como os mecanismos de mercado e os investimentos em P\&D, tornaram-se abstrações que não dão conta de explicar as escolhas e as controvérsias inovativas.

Para entender essas controvérsias e argumentações, Latour utiliza a perspectiva da tradução, que constitui para ele o dispositivo teórico mais fecundo para analisar os princípios de inovação. Os agentes sociais que compartilham o mesmo contexto de inovação dispõem de interesses e motivações diferentes, mas traduzem uns aos outros suas disposições continuamente em uma grande cadeia.

Nesse processo de tradução ou deslocamento de interesses, as noções rígidas de funções e sistemas não desempenham papel relevante, uma vez que a interpenetração dos agentes no trabalho de inovação prescinde de esquemas preestabelecidos.

A tradução efetua-se mediante a conciliação dos contrários, que misturam seus posicionamentos e argumentações de forma anárquica e imprevisível, sem papéis e disposições fixas (Idem).

$\mathrm{Na}$ esteira das formulações de Latour e dos construtivistas, alguns autores empenharam-se ao longo dos anos de 1990 em detectar situações concretas em que a produção de inovação adquiriu significação sociológica especial. O conceito de ambientes de inovação, formulado inicialmente no interior da física, trouxe importantes contribuições nesse sentido. Esse conceito representa um enfoque diferenciado acerca das possibilida- 
des de construção da prática da inovação, visando a articular tecnologia, economia e vida social de uma maneira diferenciada e aberta, distante do padrão que relaciona a inovação tecnológica exclusivamente ao setor produtivo (Maciel, 2001).

Ele consiste de um espaço institucional e de relações de forças intangíveis que um grupo disponibiliza para implementar práticas que sejam inovadoras. A socióloga Maria Lúcia Maciel defende a utilização do conceito de ambientes de inovação em estudos sociais sobre produção tecnológica, e apresenta a seguinte definição:

[...] procura dar conta do conjunto de condições - limites, obstáculos, possibilidades, estímulos da inovação em uma determinada formação social. Ambiente de inovação refere-se portanto ao conjunto de fatores políticos, econômicos, sociais e culturais que estimulam ou dificultam a inovação [...] (1997, p. 109).

Os ambientes de inovação são muito mais abrangentes e inclusivos em comparação com a perspectiva dos sistemas de inovação. Nesses, elementos advindos da herança cultural e da criatividade peculiar de um grupo social não são reconhecidos como componentes de inovação, em contraposição ao que ocorre nos ambientes.

Por exemplo, no estudo de Maciel (1996) sobre a Itália, o fortalecimento do processo inovativo nos anos de 1980 dependeu fortemente do enquadramento e da flexibilidade de seu ambiente. Nesse trabalho, a autora utiliza a noção de ambiente e detecta um importante componente cultural e estético que explica o grande impulso à inovação que o país atravessou, independentemente do contexto macroeconômico regional do período.

De acordo com sua análise, a capacidade estética (design), a herança cultural italiana e a instituição familial forneceram um ambiente extremamente fecundo para o estímulo de uma produção diferenciada, apesar da reconhecida ineficiência das iniciativas estatais na área de ciência e tecnologia.

Naquele país constituiu-se um ambiente de inovação especialmente propício para arranjos ins- titucionais e diálogos entre empresas, governos e incubadoras de forma plural e criativa, o que em outros países não se deu na mesma intensidade.

A autora diferencia a inovação em sentido estreito - tecnológico - e em sentido amplo - socioeconômico, o que lhe permite asseverar que a chave para a explicação do grande surto inovativo da Itália nesse momento se deve mais a fatores culturais e familiares do que à atuação dos agentes produtivos. Por exemplo, a entrada maior das mulheres no mercado de trabalho e as tendências pós-fordistas que fortaleceram a propriedade familiar representam fontes explicativas mais consistentes do que os gastos em P\&D convencionais.

Por meio da noção de ambiente de inovação foi possível para a autora perceber o potencial criativo advindo de aspectos tradicionais da sociedade italiana e os rearranjos institucionais e administrativos que se construíram a partir da omissão do Estado. Empresas, órgãos governamentais, trabalhadores, universidades, associações familiares, partidos e institutos de pesquisa conformaram uma grande rede, disforme e cambiante, que possibilitou a construção de um modelo específico, fruto de arranjos interdisciplinares e interinstitucionais propícios ao incremento das inovações tecnológicas, muitas delas já presentes anteriormente. Sem essa conjugação de esforços e interesses, específicos ao caso italiano em um determinado período, o desempenho econômico do país provavelmente não teria o mesmo efeito.

Diferentemente da perspectiva de Latour, que engloba o contexto tecnológico em torno de intervenções específicas, como o projeto Aramis, e se aprofunda nas tramas operacionais dos dispositivos técnicos, o conceito de ambientes de inovação representa um quadro de relações aberto no tempo e no espaço. Em suas análises, Maciel não se deteve especificamente em um único projeto, apontando controvérsias específicas em processos de tradução dos diferentes agentes, mas se propôs a recortar aspectos intangíveis das relações sociais mais amplas que repercutem no desenvolvimento tecnológico e econômico de uma determinada configuração. 
Análise semelhante à de Maciel tem sido conduzida por Manuel Castells (2003) sobre tecnologias de informação e redes sociais. Ambos apontam para caminhos instigantes de análise das ciências sociais sobre avanço tecnológico e arranjos institucionais. Castells não se utiliza do conceito de redes da mesma forma que os autores ligados à sociologia construtivista como Latour e Callon, que consideram as redes sociotécnicas prolongamentos de entidades humanas e não-humanas como resultados solidificados de processos de tradução (Latour, 2000; Flichy, 1995).

Em Castells, o conceito de rede possui um significado sociológico tradicional, como interconexão de nós diferenciados, composta por agrupamentos humanos diversos. A chegada da era da informação, que articula a microeletrônica e o pós-fordismo, representa para Castells o contexto social propício para a ampliação da sociabilidade em rede do século XXI (Castells, 1999).

Segundo esse autor, no mundo contemporâneo as novas arenas informacionais e o uso múltiplo e desregulamentado das redes tecnológicas têm possibilitado o florescimento de organizações e entidades sociais inusitadas e cada vez mais atuantes. A banalização do acesso às redes de computadores permite a comunidades de baixa renda criarem e recriarem suas formas de inserção social em formatos e circunstâncias antes inexistentes.

$\mathrm{Na}$ Europa, diversas cidades assistem à disseminação de entidades coletivas e organizações montadas em torno das redes informáticas, que possuem estruturações e regras de participação em muito diferentes das instituições conhecidas (Castells, 2003). Em Amsterdã, o autor relata a constituição e o declínio nos anos de 1990 de um grupo virtual da cidade cuja maioria dos participantes viviam em outras localidades, ocasionando formas diversas de pertencimento e identificação com o espaço urbano, a Cidade Digital.

O crescimento da cultura digital pública em Amsterdã nos anos de 1990 foi marcado mais por mudanças culturais e novas legislações do que propriamente por inovações tecnológicas. É verdade que a difusão da world wide web forneceu condi- ções técnicas imprescindíveis para o florescimento das redes comunitárias, mas as feições destas foram mais nitidamente forjadas pelas condições específicas das localidades em que se situavam.

Nesse caso, o surgimento e o desaparecimento de entidades e instituições, a construção de lideranças e as formas autogestionárias de compartilhamento das decisões coletivas constroem-se por regras e rituais sociais totalmente distintos dos usuais. Os diferentes projetos assumidos pelos agentes geram controvérsias e alterações de rumo, sociais e técnicas, que redundam em novas práticas e institucionalidades.

A emergente cultura hacker, as redes de ativismos já existentes em Amsterdã e a participação da administração pública propiciaram o cenário social para a implantação dessa política digital inovadora. Essa heterogeneidade foi fundamental para sua implantação, mas também contribuiu posteriormente, por uma série de fatores, para seu declínio.

Com o tempo, o tipo de comportamento dos usuários e o aumento da concorrência com outros web sites levaram à crise da Cidade Digital como tinha sido originalmente estabelecida pelos seus fundadores, ativistas e universitários, e por questões financeiras e estratégias de marketing veio a se transformar em mais uma holding.

O relato de Castells sobre a ascensão e a queda da Cidade Digital de Amsterdã é especialmente interessante para se perceber as oportunidades analíticas de se enquadrar economia, tecnologia e cultura em novas óticas. Em diversos momentos desse percurso as tecnologias desenvolvidas foram a reboque das práticas coletivas qualitativamente relevantes. O perfil das lideranças digitais, atrelado aos mecanismos de cooptação da administração pública, forneceu um referencial importante para a elucidação da trajetória tecnológica e da prática informacional no continente europeu, elementos imperceptíveis para a análise econômica tradicional.

Essas novas redes e fórmulas de sociabilidade são alguns dos exemplos das amplas possibilidades de investigação das ciências sociais acerca 
das manifestações de inovação que vêm se disseminando no mundo contemporâneo. Castells chama atenção para a diversidade de situações técnicas e sociais que se engendram para além dos muros do Estado, das empresas e das universidades e que demandam conceitos e fórmulas de investigação oriundas das ciências sociais.

Em várias dessas abordagens trazidas pelos cientistas sociais nos anos de 1990, depreende-se que em muitos casos as inovações se tornam menos tecnológicas e mais sociológicas. O caso italiano trabalhado por Maciel (1996) levanta de maneira recorrente esse problema, pois em muitos momentos a inovação ocorreu independentemente dos gastos em P\&D. Na Cidade Digital dá-se algo semelhante: o ambiente inovador suscitou mudanças nas lideranças locais e novas atividades culturais com baixo incremento tecnológico. No limite, podem ser detectadas importantes práticas inovativas sem invenção tecnológica (inovação sem tecnologia).

O conceito de ambiente de inovação e os parâmetros da sociologia construtivista trazem opções teóricas e metodológicas para o reconhecimento de um vasto campo de inserção dos cientistas sociais na discussão sobre inovação tecnológica e relações sociais, apesar de suas especificidades. A noção de ambientes de inovação proporciona um olhar mais amplificado sobre a prática inovativa, que não se deixa circunscrever a jogos de relações específicas e pontuais entre humanos e não-humanos, como o que ocorre nos processos de tradução de contextos analisados por Latour (ver Maciel, 2001).

O estudo de casos específicos de projetos tecnológicos e avanços econômicos podem propiciar o reconhecimento de um amplo espectro de relações coletivas que interferem decisivamente nos rumos do processo inovativo, mas que não são reconhecidos como tais.

Os cientistas sociais que trabalham com movimentos sociais e grupos específicos podem incorporar a discussão sobre inovação com estudos focados, e articular de modo contextualizado as práticas tecnológicas com as instituições no seu entorno, sem se ater especificamente a mecanismos de mercado ou a novas tecnologias.

A instalação de computadores nas escolas, a formação de redes de consumidores articulando seus direitos e o estabelecimento de formas mutualistas de produção agrícola etc. são exemplos de intersecções entre organização social e práticas tecnológicas que abrem espaço para abordagens ao mesmo tempo focadas e abrangentes. Por intermédio da construção de contextos ou ambientes específicos é viável entender a presença ou a omissão de fatores socioculturais nos rumos do desenvolvimento tecnológico.

\section{A indeterminação do processo inovativo}

A instabilidade, o risco e a contingência são temas recorrentes no pensamento social contemporâneo. A partir dos anos de 1990 os teóricos do risco passaram a apontar que o mundo atual precisa se preparar para lidar com as inconstâncias e as instabilidades recorrentes, oriundas da prática científica e tecnológica, e que somente mediante a vigilância e a precaução constante é possível gerenciar os riscos da modernidade. Toda prática assentada em resultados incertos e instáveis representa potencialmente um risco para as instituições e relações sociais. A indeterminação e a incerteza passam a ser a norma social (Beck, 1992).

$\mathrm{Na}$ esfera técnica, contudo, a instabilidade e a indeterminação são elementos altamente positivos. Diversos filósofos da tecnologia apontam para o caráter imprevisível e instável da dinâmica tecnológica como garantia de sua originalidade e consistência. Não pode haver desenvolvimento técnico sem uma margem de indeterminação dos objetos técnicos, uma brecha em sua funcionalidade é o que garante a inserção social. É por meio dela que os objetos trocam informações com seu entorno e podem aprimorar sua inserção em conjuntos técnicos mais amplos. Segundo essa tradição de pensamento, a inovação depende dos riscos para sua efetiva realização (Simondon, 1969; Stiegler, 1998). 
Para a tradição econômica, contudo, o processo inovativo não pode ser aberto à indeterminação. Ele deve ser planejado e controlado mediante regras rígidas de financiamento e investimentos criteriosos em P\&D. O excesso de administração e intervenção de policy makers e gestores industriais leva a um fechamento de suas possibilidades, de modo que os resultados e os indicadores são mais importantes do que os processos e os experimentos.

Os policy-makers e gestores industriais que organizam a prática inovativa e estabelecem metas, projeções e mecanismos de avaliação buscam coordenar o avanço tecnológico e retirar seu aspecto de indeterminação e imprevisibilidade. O estreitamento entre desenvolvimento e inovação, alavancado continuamente por governos e empresas, tende a provocar uma descaracterização desta, na medida em que a racionalização e a modernização da esfera produtiva impõe padrões e projeções de resultados que não permitem uma abertura às múltiplas demandas coletivas, à contingência dos acordos sociais e nem à margem de indeterminação dos objetos técnicos (Stiegler, 1998).

A proposta dos cientistas sociais interessados em compreender os rumos da inovação na sociedade contemporânea significa uma mudança de enfoque analítico, voltado agora para os elementos intangíveis e cambiantes da prática tecnológica e social, em que as relações são mais fundamentais do que as coisas, em que os processos superam os resultados em termos de intelegibilidade das práticas sociais (Maciel, 2001).

Há uma dimensão qualitativa fundamental na prática inovativa que os modelos da agenda schumpeteriana são incapazes de abordar. É necessário ter em mente que a indeterminação representa um componente-chave da dinâmica da inovação, a sua abertura para arranjos e modelos impensáveis e incontroláveis aprioristicamente.

Voltando à análise do metrô Aramis, Latour (1992) desenvolve a noção de porta-vozes da prática tecnológica, que representa o caminho para se compreender a tradução operada pelos agentes sociais presentes nos contextos de inovação.
Segundo esse autor, as regras de mercado e o acesso às tecnologias avançadas não representam o locus preferencial onde se constroem as condições de inovação; esta se desenvolve a partir da articulação contraditória e ambivalente dos portavozes das agências que se encontram na atividade inovativa.

$\mathrm{Na}$ construção de Aramis, constituiu-se uma arena de relações instáveis, um encontro de racionalidades diversas que adquiriram uma conformação circunstancial a partir da troca de experiências entre setores produtivos, consumidores, gestores públicos, experts, entre outros. Engenheiros, advogados, urbanistas e outros agentes deslocaram suas posições conjuntamente, produzindo um contexto de inovação que não pode ser explicado pelo esquema binário reprodução/mudança.

Ou seja, não existem princípios evolutivos que determinem aprioristicamente os rumos do processo inovativo; este se constrói por intermédio de estratégias de recrutamentos, alianças e assimilações de disposições concorrentes. Os portavozes das diferentes agências se revezam na definição de posturas voltadas à mudança e à reprodução, descontruindo lógicas e posicionamentos aparentemente estabilizados. Os processos de tradução impedem o estabelecimento de agendas coletivas definitivas, de modo que a inovação se constrói a partir do choque de identidades e dimensões dos atores, e estas constituem em si mesmas temas de pesquisa.

Para Latour, mais importante do que determinar as causas da crise de Aramis, é identificar como os agentes envolvidos (a Companhia Automatismo e Técnica, o poder público) construíram uma cadeia de traduções que transforma uma questão global em problemas específicos (técnicos e sociais).

As conclusões de outras análises vão em sentido semelhante, apesar de trilharem outros caminhos. Segundo Maciel (1996), no caso da Itália durante os anos de 1980 o desenvolvimento conquistado tomou rumos imprevistos e até mesmo contraditórios aos indicadores econômicos tradicionais. Fatores geográficos, comportamentos 
empresariais inusitados e formas de inovação alternativas às práticas de pesquisa tradicionais levaram a Itália a desempenhos inovativos cada vez maiores, que pouca influência teve do investimento de P\&D por parte das agências oficiais. De acordo com a autora,

Contribuíram para o sucesso econômico importantes avanços no campo da inovação social como as diversas formas de educação continuada, incluindo a qualificação e atualização tecnológica dos trabalhadores; o desenvolvimento de formas originais nas relações capital/trabalho e na organização do trabalho nas empresas [...] e a implantação de parques tecnológicos visando não só à pesquisa e à produção mas também à formação de recursos humanos qualificados, em colaboração com as universidades (1996, p. 78).

Para Maciel, o caso italiano demonstra cabalmente que a inovação é sempre um processo em aberto, mediado por um sem-número de variáveis que os agentes econômicos são incapazes de controlar, como taxa de natalidade, apropriação de tecnologias preexistentes, arroubos estéticos etc. A inovação social pode tomar rumos imprevisíveis, que os analistas econômicos não podem antecipar, e os fatores essenciais são mais qualitativos do que quantitativos. A utilização original de tecnologias já existentes, conjugada ao desempenho otimizado ante o baixo investimento tecnológico, propiciou uma conjuntura surpreendente de alto crescimento econômico com poucos recursos materiais.

A inovação socioeconômica é o vetor de transformação tecnológica, e não o contrário. Isso acarreta o problema teórico de como gerar modelos para controlar e antecipar essas tendências. Seguindo o raciocínio da autora, a concepção dominante de desenvolvimento tende a colonizar o sentido da inovação e alijá-la de um de seus componentes mais ricos e férteis, a incerteza e a experimentação constante.

$\mathrm{Na}$ discussão de Castells (1999), esse aspecto é também visível. A banalização de novas tecnologias tem levado a novos arranjos empresariais e dispositivos jurídicos inusitados, que prejudicam o estabelecimento de uma agenda social compartilhada.
Os gastos dos Estados nacionais com segurança eletrônica, as mudanças no comportamento político dos cidadãos a partir da Internet e outros exemplos fazem divisar um amplo conjunto de problemáticas e tendências que se inclinam a ditar os rumos de diversas inovações.

O crescimento do individualismo em suas novas manifestações, os processos de mobilidade urbana em fluxos e a exclusão de grandes contingentes populacionais da economia informacional devido a déficits educacionais não são apenas $\mathrm{O}$ efeito da instalação das novas tecnologias, mas correspondem a comportamentos coletivos e escolhas políticas específicas que, por sua vez, impõem parâmetros para os rumos da inovação tecnológica.

Castells (1999) defende que o determinismo tecnológico presente na retórica das grandes corporações e dos experts em gestão estratégica não dá conta das múltiplas situações conflituosas entre empresas e consumidores; autoridades públicas e população marginalizada dos grandes centros urbanos em face da utilização de novas tecnologias informacionais. Em muitos casos, o avanço tecnológico e o formato das inovações seguem os rumos anárquicos estipulados pelos contratos e pelas conveniências dos acordos coletivos.

Essa circularidade entre comportamento social e desenvolvimento tecnológico pede uma agenda de pesquisa complexa, antenada aos processos de consolidação de novas práticas coletivas e de relações cambiantes entre agentes múltiplos e de identidade em formação. Contra a vontade de grandes corporações, policy makers e técnicos, os rumos dos processos inovativos não são programáveis e controlados gerencialmente, mas sofrem as tendências impostas por articulações imprevisíveis entre os diferentes agentes.

\section{Conclusão}

Desde os seus primórdios, as ciências sociais têm se ocupado da questão tecnológica. Em alguns momentos acentuando uma perspectiva otimista de aceleração tecnológica conectada ao crescimen- 
to econômico, em outros, chamando atenção para o panorama de incerteza e indeterminação que cerca os sistemas técnicos e a realidade social. Não tem sido fácil para os cientistas sociais transporem essas posições e buscarem novas ferramentas analíticas para cruzar as relações sociais com a inovação dos processos tecnológicos.

As análises sociológicas sobre o projeto do metrô Aramis na França, a Cidade Digital de Amsterdam e a Terceira Itália abrem perspectivas instigantes para as ciências sociais cruzarem o desenvolvimento tecnológico com o intangível das relações sociais. Apesar de suas diferenças, a partir da discussão desses casos é possível perceber que a problemática da inovação tecnológica pode ser submetida a uma infinidade de enfoques, e que as ciências sociais têm grandes contribuições a dar.

Este trabalho procurou mostrar algumas dessas contribuições. Uma delas reside na questão dos ambientes de inovação, os quais não respeitam somente aspectos econômicos e administrativos, mas igualmente as condições intelectuais e as tradições culturais em que elas se enraízam e se desenvolvem. Toda uma linhagem de pesquisa, e o trabalho de Maciel (1996) é um expoente nessa direção, aponta para a necessidade de inclusão de variáveis diferenciadas na definição das práticas inovativas. Estudos etnográficos e análises comparativas podem propiciar novos enfoques qualitativos dentro dessa agenda de pesquisa.

Outra contribuição que se pretendeu trazer foi a problemática da indeterminação do processo inovativo. A avaliação dos investimentos em inovação pode receber um tratamento diferenciado, à medida que a dinâmica tecnológica for encarada em sua contingência e experimentação, e não mediante parâmetros e modelos acabados de análise.

Por fim, discutiu-se como o conceito de tradução e a análise sociológica de cenários específicos alavancam o debate em torno da construção coletiva de processos tecnológicos e sociais.

Apesar de os trabalhos sobre esses temas serem ainda escassos no âmbito das ciências sociais, nota-se uma tendência crescente de aglutinar a perspectiva cultural do desenvolvimento tecnoló- gico com seus dados mais propriamente objetivos. Um caminho ainda em aberto e com inúmeras possibilidades.

\section{BIBLIOGRAFIA}

BECK, Ülrich. (1992), Risk society: towards a new modernity. Londres, Sage.

BRUESEKE, Franz. (2002), "A modernidade técnica". Revista Brasileira de Ciências Sociais, 17 (49): 135-144.

CALLON, Michel. (1987), "Society in the making: the study of technology as a tool for sociological analysis", in Wiebe Bijker et al. (eds.), The social construction of technological systems, Mass., Cambridge, MIT Press.

CASSIOLATO, José Eduardo \& LASTRES, Helena. (2000), "Sistemas de inovação: políticas e perspectivas". Parcerias Estratégicas, 8: $237-255$.

CASTELLS, Manuel. (1999), A sociedade em rede. Trad. Roneide Majer. São Paulo, Paz e Terra.

(2003), A galáxia da Internet. Trad. Maria Luiza Borges. Rio de Janeiro, Jorge Zahar.

FEENBERG, Andrew. (1991), Critical theory of technology. Oxford, Oxford University Press.

(1999), Questioning technology. Londres, Routledge.

FLICHY, Patrice. (1995), L'innovation technique. Paris, La Découverte.

FREEMAN, Christopher. (1982), Economics of industrial innovation. Cambridge, MIT. (1992), The economics of hope. Londres, Pinter.

HABERMAS, Jürgen. (1983), Técnica e ciência enquanto "ideologia". Trad. José Lino 
Grünnewald. São Paulo, Abril (col. Os Pensadores).

LATOUR, Bruno. (1992), Aramis ou l'amour des techniques. Paris, La Découverte. . (2000), Ciência em ação. Trad. Ivone Benedetti. São Paulo, Editora da Unesp.

LEMOS, Cristina. (2000), "Inovação na era do conhecimento”. Parcerias Estratégicas, 8: 157-179.

MACIEL, Maria Lúcia. (1996), O milagre italiano: caos, crise e criatividade. Brasília, Paralelo 15.

. (1997), "Inovação e conhecimento", in Fernanda Sobral et al. (orgs.), A alavanca de Arquimedes: ciência e tecnologia na virada do século, Brasília, Paralelo 15 .

. (2001), "Hélices, sistemas, ambientes e modelos: os desafios à sociologia da inovação. Sociologias, ano 3, 6: 18-29.

NICOLAS, Françoise \& MYTELKA, Lynn. (1994), L'innovation: le clef du développement. Paris, Masson.

SCHUMPETER, Joseph Alois. (1982), Teoria do desenvolvimento econômico. Trad. Maria Sílvia Possas. São Paulo, Abril (col. Os Pensadores).

SIMONDON, Gilbert. (1969), Du mode d'existence des objets techniques. Paris, AubierMontaigne.

STIEGLER, Bernard. (1998), Technics and time 1. Londres, Routledge.

TRIGUEIRO, Michelangelo Santoro. (2002), O clone de Prometeu. Brasília, Editora da UnB. 


\section{INOVAÇÃO E CIÊNCIAS SO- CIAIS: EM BUSCA DE NOVOS REFERENCIAIS}

Thales de Andrade

\section{Palavras-chave}

Inovação; Contexto; Ciências

sociais; Tecnologia; Ambientes

de inovação.

O presente artigo trata da problemática da inovação tecnológica, retomando o surgimento do conceito e a importância da economia em sua consolidação. Discute os conceitos de contexto e ambientes de inovação, apontando para a necessidade de a sociologia se debruçar sobre essas ferramentas teóricas. Aborda, ainda, a questão da incerteza inscrita na prática inovativa, um tema presente no pensamento de diversas correntes da filosofia e da sociologia das técnicas. É necessário sublinhar a importância da participação das ciências sociais no estabelecimento da agenda de pesquisa em inovação, e alguns autores têm demonstrado interesse em lançar um olhar circunstanciado sobre as diferentes práticas sociais ligadas à dimensão inovativa.

\section{INNOVATION AND SOCIAL SCIENCES: IN THE SEARCH FOR NEW APPROACHES}

Thales de Andrade

\section{Keywords}

Innovation; Context; Social

sciences; Technology; Innova-

tion environment.

This article deals with the question of technological innovation, reviewing its origins and the important role played by economics in its further consolidation. It presents the concepts of innovation context and environments, pointing out the task for sociology to handle with these theoretical tools. And the article also discusses the question of uncertainty within innovation practices, a special point for philosophy and sociology of technics. It focuses the need to set an agenda for innovation research incorporating the social sciences, and some authors have showed interest to shed some light on different social practices related to the innovation dimension.

\section{INNOVATION ET SCIENCES SOCIALES: VERS NOUVELLES APPROCHES}

Thales de Andrade

\section{Mots-clés}

Innovation; Contexte; Sciences sociales; Technologie; Millieu d'innovation.

Ce travail aborde le probléme de l'innovation technologique, et remontre la génése de son concept et l'importance des sciences économiques dans son développement. Il débat les concepts du contexte et du milieu de l'innovation en mettant le point sur la nécessité de la sociologie de se pencher sur ses outils théoriques. Il aborde aussi la question de l'incertitude placée dans la pratique de l'innovation technique, car c'est un sujet present dans l'esprit de plusiers courants de la philosophie et la sociologie des techniques. Il faut souligner l'importance des sciences sociales dans l'établissement d'un plan de recherche sur la question d'innovation, d'ailleurs quelques chercheurs ont montré leur intérêt en créant une approche circonstancielle sur les differentes actions sociales liées à l'innovation. 